\title{
Polyglycolic acid sheet application to prevent esophageal stricture after endoscopic submucosal dissection for recurrent esophageal cancer
}

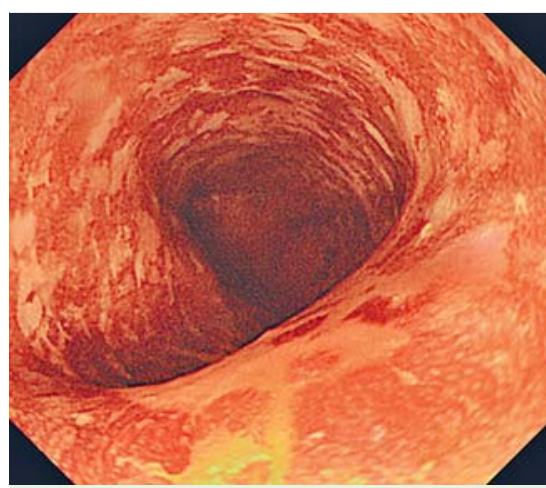

Fig. 1 Endoscopic view showing multiple Lugol-unstained lesions, $22-32 \mathrm{~cm}$ from the upper incisor, 96 months after concurrent chemoradiotherapy for esophageal cancer.

Endoscopic submucosal dissection (ESD) is an accepted treatment for early esophageal cancer. However, for large early esophageal cancers, ESD is associated with an increased risk of stricture development.

A 73-year-old man was diagnosed with esophageal cancer (cT1N1M0, stage IIb). He received concurrent chemoradiotherapy (CCRT), including four cycles of monthly fluorouracil, cisplatin, and radiation (54Gy).

At 96 months after CCRT, he had multiple Lugol-unstained lesions, $22-32 \mathrm{~cm}$ from the upper incisor ( $\bullet$ Fig. 1 ). The pathological results indicated well-differentiated squamous cell carcinoma at $22 \mathrm{~cm}$ and $25 \mathrm{~cm}$ from the upper incisor, and squamous epithelial dysplasias at $25-32 \mathrm{~cm}$ from the upper incisor.

We performed ESD $(22-32 \mathrm{~cm}$ from the upper incisor, representing over $90 \%$ of the esophageal circumference) ( $\bullet$ Fig. 2 a). Successful en bloc resection was achieved without adverse events ( $\bullet$ Fig. $\mathbf{2}$ b).

On the day after ESD, in order to prevent stricture development, a $100 \times 50 \mathrm{~mm}$ polyglycolic acid (PGA) sheet (Neoveil; Gunze Co., Kyoto, Japan) was placed with hemoclips, followed by application of a fibrin glue (Beriplast P Combi-set; CSL Behring Pharma, Tokyo, Japan) ( Fig.3, - Video 1).
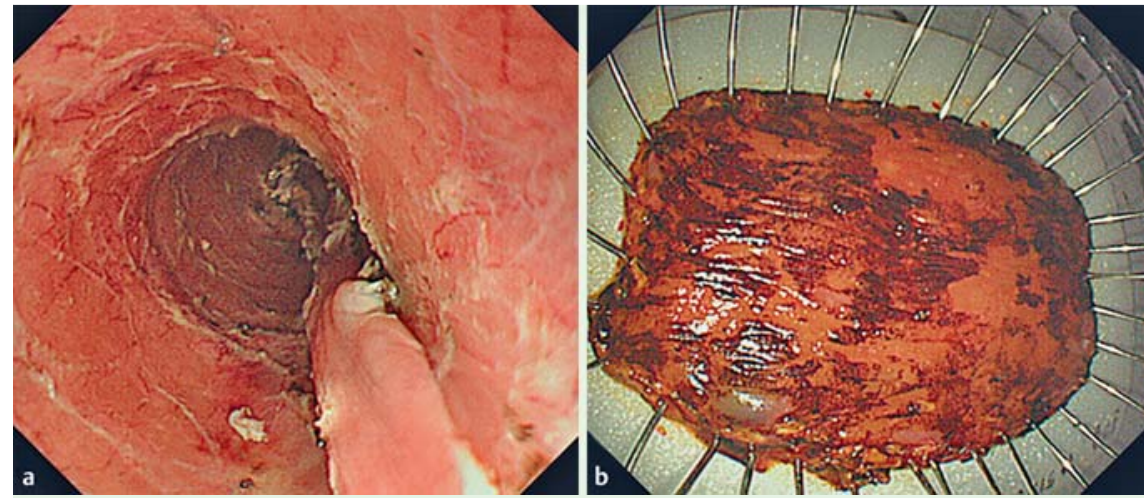

Fig. 2 Endoscopic submucosal dissection of the esophageal lesions. a Approximately $90 \%$ of the circumference of the esophagus was removed. $\mathbf{b}$ The resected specimen.

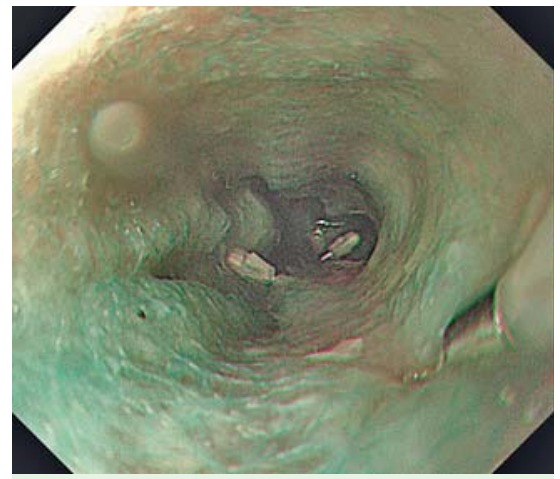

Fig. 3 Endoscopic view of the polyglycolic acid sheet placed to prevent stricture development after endoscopic submucosal dissection.

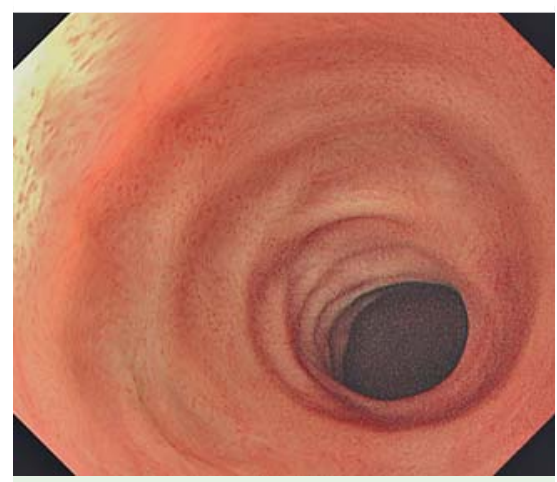

Fig. 5 Endoscopic view showing resolution of the stricture after through-the-scope balloon dilation (the endoscope could pass after balloon dilation). The patient had no symptoms at 12 months after the procedure.

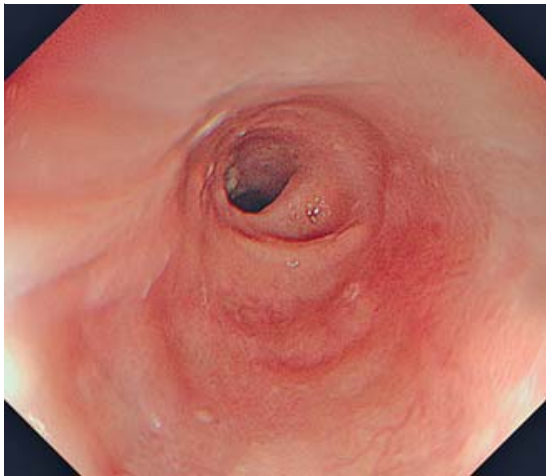

Fig. 4 Endoscopic view at 7 weeks after endoscopic submucosal dissection, showing scar change $20-26 \mathrm{~cm}$ from the upper incisor and a focal stricture at $26 \mathrm{~cm}$.

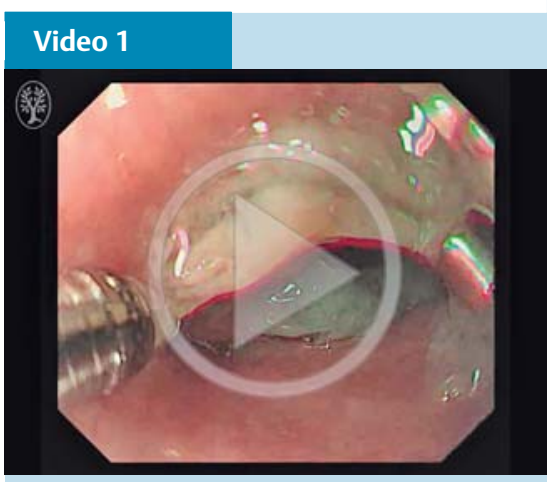

Application of a polyglycolic acid sheet with hemoclips, followed by application of fibrin glue on post endoscopic submucosal dissection lesion. 
Follow-up endoscopy performed 7 weeks after ESD showed a focal stricture at $26 \mathrm{~cm}$ from the upper incisor ( Fig.4). The endoscope could not pass through the narrow lumen. We performed throughthe-scope balloon dilation. Thereafter, the endoscope could pass through the narrow lumen.

The patient did not experience any recurrent symptoms during the subsequent 12 months, and the most recent endoscopy showed the absence of a stricture ( $\bullet$ Fig.5).

Esophageal stenosis frequently occurs in patients with defects involving over three-quarters of the circumference of the esophagus after ESD [1]. Patients usually require multiple endoscopy sessions for the management of a stricture, especially when present in a long segment [2]. Iizuka et al. reported that the use of PGA sheets is safe and effective for reducing the incidence of esophageal stricture development after ESD [3].

Our patient had a long segment length and a history of CCRT treatment, which resulted in severe fibrotic lesions associated with a high risk of esophageal stricture development and perforation after balloon dilation. Although an esophageal stricture was noted 7 weeks after ESD, the focal stricture was only $1-2 \mathrm{~cm}$ on a lesion size of $10 \mathrm{~cm}$. Moreover, only one balloon dilation procedure was necessary for the relief of dysphagia.

In conclusion, the use of a PGA sheet appears to be a promising method for preventing the development of long strictures and reducing the number of endoscopic dilations required, especially after ESD for recurrent esophageal cancer previously treated with CCRT.

Endoscopy_UCTN_Code_TTT_1AO_2AG

Competing interests: None

\section{Yeong Jin Kim, Jun Chul Park, Hyunsoo Chung, Sung Kwan Shin, Sang Kil Lee, Young Chan Lee}

Division of Gastroenterology, Department of Internal Medicine, Yonsei University

College of Medicine, Seoul, Korea

\section{References}

1 Katada C, Muto M, Manabe T et al. Esophageal stenosis after endoscopic mucosal resection of superficial esophageal lesions. Gastrointest Endosc 2003; 57: 165-169

2 Isomoto H, Yamaguchi N, Nakayama T et al. Management of esophageal stricture after complete circular endoscopic submucosal dissection for superficial esophageal squamous cell carcinoma. BMC Gastroenterol 2011; 11: 46

3 Iizuka T, Kikuchi D, Yamada A et al. Polyglycolic acid sheet application to prevent esophageal stricture after endoscopic submucosal dissection for esophageal squamous cell carcinoma. Endoscopy 2015; 47: $341-344$

\section{Bibliography}

DOI http://dx.doi.org/

10.1055/s-0042-117224

Endoscopy 2016; 48: E319-E320

(c) Georg Thieme Verlag KG

Stuttgart · New York

ISSN 0013-726X

Corresponding author

\section{Jun Chul Park, MD}

Division of Gastroenterology

Department of Internal Medicine

Yonsei University College of Medicine

50 , Yonsei-ro

Seodaemun-gu

Seoul

Korea

Fax: +82-2-22277877

junchul75@yuhs.ac 